\title{
Fungal infections in marrow transplant recipients under antifungal prophylaxis with fluconazole
}

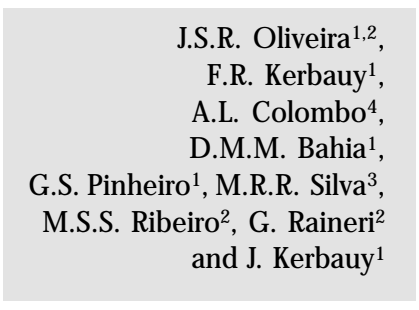

S.R. O liveira ${ }^{1,2}$ F.R. Kerbauy ${ }^{1}$, A.L. Colombo ${ }^{4}$, D.M.M. Bahia ${ }^{1}$, G.S. Pinheiro ${ }^{1}$, M.R.R. Silva ${ }^{3}$, and J. Kerbauy ${ }^{1}$

\author{
1Disciplina de Hematologia e Hemoterapia, Escola Paulista de Medicina, \\ Universidade Federal de São Paulo, São Paulo, SP, Brasil \\ ${ }^{2}$ Serviço de Hematologia, Casa de Saúde Santa Marcelina, São Paulo, SP, Brasil \\ ${ }^{3}$ Departamento de Patologia, and ${ }^{4}$ Divisão de Moléstias Infecciosas, \\ Escola Paulista de Medicina, Universidade Federal de São Paulo, São Paulo, \\ SP, Brasil
}

\section{Correspondence \\ J.S.R. Oliveira \\ Serviço de Hematologia e Transfusão EPM, UNIFESP \\ 04023-900 São Paulo, SP \\ Brasil \\ Fax: + 55-11-5571-8806 \\ E-mail: salvador@ hemato.epm.br}

Publication supported by FAPESP

Received June 29, 2001

Accepted May 8, 2002

\section{Abstract}

Fungal infection is one of the most important causes of morbidity and mortality in bone marrow transplant (BMT) recipients. The growing incidence of these infections is related to several factors including prolonged granulocytopenia, use of broad-spectrum antibiotics, conditioning regimens, and use of immunosuppression to avoid graftversus-host disease (GvHD). In the present series, we report five cases of invasive mold infections documented among 64 BMT recipients undergoing fluconazole antifungal prophylaxis: 1) A strain of Scedosporium prolificans was isolated from a skin lesion that developed on day +72 after BMT in a chronic myeloid leukemic patient. 2) Invasive pulmonary aspergillosis (Aspergillus fumigatus) was diagnosed on day +29 in a patient with a long period of hospitalization before being transplanted for severe aplastic anemia. 3) A tumoral lung lesion due to Rhizopus arrhizus (zygomycosis) was observed in a transplanted patient who presented severe chronic GvHD. 4) A tumoral lesion due to Aspergillus spp involving the 7th, 8th and 9th right ribs and local soft tissue was diagnosed in a BMT patient on day +110. 5) A patient with a history of Ph1-positive acute lymphocytic leukemia exhibited a cerebral lesion on day +477 after receiving a BMT during an episode of severe chronic GvHD. At that time, blood and spinal fluid cultures yielded Fusarium sp. Opportunistic infections due to fungi other than Candida spp are becoming a major problem among BMT patients receiving systemic antifungal prophylaxis with fluconazole.

\section{Introduction}

Fungal infection is one of the most important causes of mortality among immunocompromised patients, particularly those submitted to bone marrow transplantation (BMT). The growing incidence of these in-

\section{Key words}

- Bone marrow

transplantation

- Fungal infections

- Fluconazole prophylaxis fections is related to several factors including prolonged granulocytopenia, use of broadspectrum antibiotics, central venous access devices, and chemotherapy and radiotherapy protocols employed as conditioning regimens, as well as immunosuppression to prevent graft-versus-host disease (GvHD) (1-4). 
Candida spp and Aspergillus spp represent the most common agents of fungal infections among patients submitted to BMT $(2,3,5-7)$. However, after the beginning of fluconazole prophylaxis as a routine measure, a wide spectrum of fungal species have emerged as opportunistic pathogens among such patients $(2,8,9)$. Consequently, infections due to non-Candida fungi should be kept in mind as possible causes of systemic infections during deep immunosuppression after BMT, particularly when patients suffer from $\operatorname{GvHD}(4,10,11)$. We describe five cases of invasive and sustainable non-Candida fungal infections among 64 allogeneic BMT recipients. All of them received fluconazole therapy during and after BMT.

\section{Patients and Methods}

Between August 1993 and July 1998, a total of 64 BMT were performed at the Hematology and Transfusion Service of Escola Paulista de Medicina, UNIFESP, and at the Hematology Service of Casa de Saúde Santa Marcelina, São Paulo, SP, Brazil. Pre-transplant hematological diseases of the patients included 29 cases of chronic myeloid leukemia (CML, 22 chronic, 3 accelerated and 4 in the blastic crisis phase), 10 cases of acute myeloid leukemia (AML, 5 in the first complete remission phase, 2 in the second and 3 with relapsed AML), 12 cases of severe aplastic anemia (SAA), 6 cases of acute lymphocytic leukemia (ALL), 2 cases of nonHodgkin's lymphoma, and 1 case each of multiple myeloma and myelodysplastic syndrome/AREB-t. Three patients (2 SAA and 1 chronic CML) were submitted to a second BMT. All donors had bone marrow harvested from the posterior/anterior iliac crests of the pelvis using standard sterile techniques. A minimal amount of $2 \times 10^{8}$ total nucleated cells $/ \mathrm{kg}$ recipient weight were collected for each patient.

All patients received a daily $200-\mathrm{mg}$ dose of fluconazole for prophylaxis of fungal in- fections from the first day of the conditioning regimen until day +100 after BMT. Prophylaxis was delayed or reintroduced whenever GvHD was diagnosed. Unusual nonCandida fungal infections occurred in five patients whose clinical features are described below (Table 1). Clinical and laboratory data were collected by reviewing the patient records. Fungal isolates were sent to a reference laboratory for further identification at the species level based on the micromorphology of their colonies.

\section{Results}

It was possible to identify five cases of mold infections and three cases due to Candida sp among the 64 BMT patients evaluated between August 1993 and July 1998. All patients studied had received fluconazole prophylactic therapy during the first 100 days after BMT or whenever there was evidence of chronic GvHD. Two chronic CML patients had yeast isolated from their Hickman lines after engraftment. Both were on fluconazole therapy and their blood cultures grew $C$. albicans. They received parenteral daily doses of $1 \mathrm{mg} / \mathrm{kg}$ amphotericin B for ten days in order to overcome their infections. The third episode of systemic Candida infection was recorded in a patient with accelerated CML. She had strains of $C$. tropicalis isolated from the mouth and gastrointestinal tract two weeks after fluconazole withdrawal (on day +40 ) due to multidrug hepatitis. Blood cultures yielded the same fungal agent during a febrile non-granulocytopenic episode documented on day +57 when antifungal treatment was initiated. All candidemias were promptly resolved by the introduction of intravenous amphotericin B therapy. Two of three candidemic episodes were documented during the regimen of fluconazole prophylaxis that was interrupted before initiating amphotericin B therapy. The following five reports present the major clinical and laboratory characteristics of all the 
mold infections reported during the study period.

\section{Case reports}

Case 1 - Scedosporium prolificans. A 42-year-old man diagnosed with chronic phase CML received allogeneic BMT from a human leukocyte antigen (HLA)-identical brother (Table 1). On day +40 , he developed grade II acute GvHD and was initially treated with $1 \mathrm{mg} / \mathrm{kg}$ prednisone. The prednisone dose was tapered to $20 \mathrm{mg}$ after day +60 . During steroid therapy, the patient developed insulin-dependent diabetes. On day +72 , he presented with a granulomatous skin lesion which showed fungal infection when biopsied (Figure 1). At that time, his white blood cell count was $3.5 \times 10^{9} / 1$, absolute neutrophil count was $2.4 \times 10^{9} / 1$, and lymphocytes were $1 \times 10^{9} / 1$. Tissue cultures from a surgical biopsy yielded $S$. prolificans. Initially, he was treated with $1 \mathrm{mg} \mathrm{kg}^{-1}$ day $^{-1}$ amphotericin B for three weeks, without any clinical improvement. On day +116 , amphotericin B was switched to itraconazole at 600 $\mathrm{mg} /$ day for six months, followed by $100 \mathrm{mg} /$ day for one year. He evolved to chronic hepatic GvHD and was maintained on 20 $\mathrm{mg}$ /day prednisone plus $200-300 \mathrm{mg}$ /day cyclosporin until day +180 . Immunosuppression was tapered after day +180 . His hepatic GvHD remained under control with $10 \mathrm{mg}$ of prednisone during the first year of follow-

Table 1. Features of unusual fungal infections seen after bone marrow transplantation (BMT).

\begin{tabular}{|c|c|c|c|c|c|}
\hline Patient & Case 1 & Case 2 & Case 3 & Case 4 & Case 5 \\
\hline Disease/age (years) & $\mathrm{CML} / 42$ & SAA/13 & AML/43 & SAA/24 & $\mathrm{ALL} / 21$ \\
\hline $\begin{array}{l}\text { Conditioning regimen } \\
\left(\mathrm{mg} \mathrm{kg}^{-1} \text { day }^{-1}\right)\end{array}$ & $\begin{array}{l}\text { Bu (16) } \\
\text { Cy (120) }\end{array}$ & $\begin{array}{l}\text { Cy (200) } \\
\text { ATG (90) }\end{array}$ & $\begin{array}{l}\text { VP-16 (60) } \\
\text { TBI } 1340 \text { cGy }\end{array}$ & $\begin{array}{l}\text { Cy (200) } \\
\text { ATG (90) }\end{array}$ & $\begin{array}{l}\text { Cy (120) } \\
\text { TBI } 1320 \text { cGy }\end{array}$ \\
\hline GvHD prophylaxis & $\mathrm{MTX}+\mathrm{CsA}$ & $\mathrm{MTX}+\mathrm{CsA}$ & $\mathrm{PRD}+\mathrm{CsA}$ & $\mathrm{MTX}+\mathrm{CsA}$ & $\mathrm{MTX}+\mathrm{CsA}$ \\
\hline Engraftment & Day +14 & Day +21 & Day +13 & Day +24 & Day +21 \\
\hline Acute GvHD & GII/day +40 & None & GII/skin, liver & None & None \\
\hline Chronic GvHD & Present & None & Present & None & Present \\
\hline $\begin{array}{l}\text { Infection site } \\
\text { (agent) }\end{array}$ & $\begin{array}{l}\text { Skin } \\
\text { (S. prolificans) }\end{array}$ & $\begin{array}{l}\text { Lung } \\
\text { (A. fumigatus) }\end{array}$ & $\begin{array}{l}\text { Lung } \\
\text { (R. arrhizus) }\end{array}$ & $\begin{array}{l}\text { Bone (ribs), soft tissue } \\
\text { (Aspergillus } \mathrm{sp} \text { ) }\end{array}$ & $\begin{array}{l}\text { CNS/sepsis } \\
\text { (Fusarium sp) }\end{array}$ \\
\hline Treatment & AMB followed by ITR & AMB followed by ITR & AMB & AMB plus ITR & AMB plus fluconazole \\
\hline $\begin{array}{l}\text { Outcome } \\
\text { (Kamofsky index) }\end{array}$ & $\begin{array}{l}\text { Alive without } \\
\text { evidence of fungal } \\
\text { infection ( } K=100 \% \text { ) }\end{array}$ & $\begin{array}{l}\text { Dead - Gram-positive } \\
\text { pneumonia on day } \\
+317\end{array}$ & $\begin{array}{l}\text { Dead - disseminated } \\
\text { zygomycosis and } \\
\text { chronic GvHD on } \\
\text { day }+310\end{array}$ & $\begin{array}{l}\text { Alive } 44 \text { months } \\
\text { after BMT, with } \\
\text { no signs of infections } \\
(\mathrm{K}=100 \%)\end{array}$ & $\begin{array}{l}\text { Dead - disseminated } \\
\text { fungal infection on } \\
\text { day }+477\end{array}$ \\
\hline Autopsy & & $\begin{array}{l}\text { Absence of } \\
\text { fungal infection }\end{array}$ & Not authorized & & Not authorized \\
\hline Risk factors & $\begin{array}{l}\text { PRD therapy, } \\
\text { diabetes, hand } \\
\text { surgery one year } \\
\text { before BMT, acute } \\
\text { GIl and chronic } \\
\text { GVHD }\end{array}$ & $\begin{array}{l}\text { Six months } \\
\text { inpatient care } \\
\text { before BMT, } \\
\text { respiratory arrest } \\
\text { at catheter insertion, } \\
\text { PRD and CSA use } \\
\text { before BMT }\end{array}$ & $\begin{array}{l}\text { PRD therapy, } \\
\text { diabetes, acute GII } \\
\text { and extensive } \\
\text { chronic GvHD }\end{array}$ & $\begin{array}{l}\text { Double catheter } \\
\text { insertion, PRD } \\
\text { therapy, sepsis } \\
\text { episode before } \\
\text { BMT, pericardial } \\
\text { effusion after BMT }\end{array}$ & $\begin{array}{l}\text { PRD, CsA, Ig and } \\
\text { thalidomide therapy } \\
\text { for extensive chronic } \\
\text { GvHD and leukemia } \\
\text { relapse }\end{array}$ \\
\hline
\end{tabular}

$\mathrm{CML}=$ chronic myeloid leukemia, $\mathrm{SAA}=$ severe aplastic anemia, $\mathrm{AML}=$ acute myeloid leukemia, $\mathrm{ALL}=$ acute lymphocytic leukemia, $\mathrm{Bu}=$ busulphan, $\mathrm{Cy}=$ cyclophosphamide, ATG = anti-thymocytic globulin, VP-16 = etoposide, TBI = total body irradiation, MTX = methotrexate, CSA = cyclosporine, PRD = prednisone, AMB = amphotericin B, ITR = itraconazole, Ig = polyclonal immunoglobulin, GvHD = graft-versus-host disease. 
Figure 1. Case 1 (Scedosporium prolificans). Skin lesion on the third finger of the left hand (upper panel) and the corresponding histopathology exhibiting fungal infection (lower panel). See white arrows in 1000X magnification. up. Prednisone was discontinued after that time. Currently, he has no evidence of fungal skin lesion and presents only a local scar.

Case 2 - Aspergillus fumigatus. A 13year-old girl with SAA, initially treated with prednisone and cyclosporin, had a long period of hospitalization in an intensive care unit before BMT, when she suffered from multiple episodes of febrile granulocytopenia, receiving broad-spectrum antibiotic therapy. At the time of a central catheter insertion, she experienced a respiratory arrest demanding mechanical ventilation. She was submitted to HLA-identical sibling allogeneic BMT. A sustained engraftment was seen since day +18 . On day +29 , she developed fever with negative blood cultures. A chest X-ray and thoracic CT scan showed bilateral condensation, initially misdiagnosed as a bacterial infection. On day +40 , typical
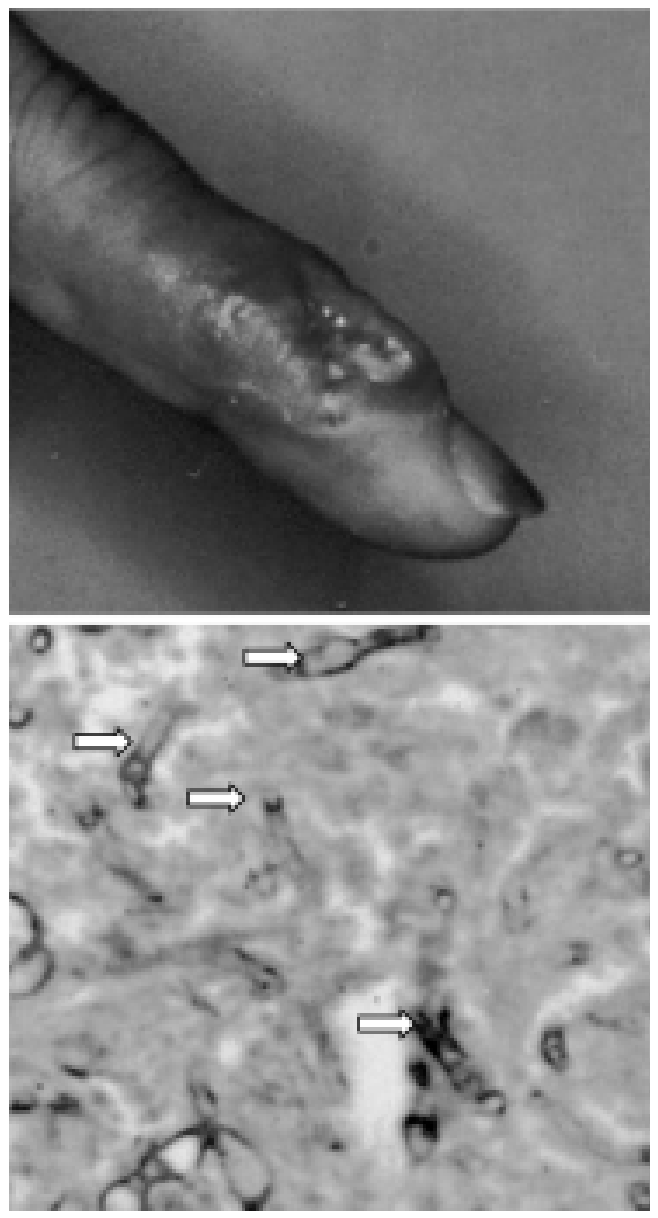

peripheral nodular lesions were observed in both lungs (Figure 2). She was started on amphotericin B until a total accumulated dose of $2.5 \mathrm{~g}$ was achieved, when she developed irreversible renal tubular acidosis and antifungal therapy was switched to itraconazole. Two thoracotomies were performed on days +43 and +71 and $A$. fumigatus was isolated from tissue cultures of both surgical samples. She died on day +347 due to a Gram-positive pulmonary infection. At autopsy, no fungal infection was seen.

Case 3 - Rhizopus arrhizus. A 43-yearold man with myelomonocytic AML was submitted to HLA-identical sibling allogeneic BMT during the second complete remission phase. As a complication, he developed grade II skin and liver acute GvHD treated with prednisone. Five months later, he evolved to extensive chronic GvHD (liver, skin, oral lichen planus and cutaneous scleroderma-like lesions) requiring $8 \mathrm{mg} \mathrm{kg}^{-1}$ day $^{-1}$ cyclosporin and $60 \mathrm{mg} /$ day prednisone. He also received psoralen-ultraviolet A light therapy and intravenous polyclonal immunoglobulin for three months with some improvement. On day +241 , an apical left pulmonary infiltrate was seen. Bronchoalveolar lavage was negative. Empirical treatment for tuberculosis was initiated at that time. Despite the therapy for tuberculosis, the lung lesion became tumoral and the patient was submitted to thoracotomy on day +296 . Cultures from surgical lung material grew $R$. arrhizus (zygomycosis). Amphotericin B was started at that time, but the patient died two weeks later with progressive liver failure. An autopsy was not authorized by the family. The radiological and macroscopic features of the fungal lesions are shown in Figure 3.

Case 4 - Aspergillus sp. A 24-year-old woman with SAA was initially treated with prednisone without any clinical response. Before BMT, she had an episode of Serratia sp sepsis. Engraftment occurred on day +17 . After day +20 , she experienced persistent 
pericardial effusion that was empirically treated as tuberculosis during the following six months. On day +50 , she reported pain on the 7 th and 8 th right ribs. Imaging tests including technetium scintigraphy were normal. On day +110 , a new CT scan was performed and a tumoral lesion involving the 7th, 8th and 9th right ribs and local soft tissue was seen (Figure 4). At that time, a technetium scintigraphy scan was also positive. A surgical resection of tumoral lesions was performed. Culture screening of local drainage samples and resected bone yielded Aspergillus sp. Tissue sections did not show fungal involvement. She had been treated with daily doses of $1 \mathrm{mg} / \mathrm{kg}$ amphotericin B plus $600 \mathrm{mg}$ itraconazole since day +110 . On day +256 , another surgical resection was done due to relapse of lesions on the same level of left ribs. New histological examinations and cultures of these second resection samples were negative for fungal infections. Amphotericin B tapering was tried during the next three months, but a remarkable worsening of clinical and radiological findings as well as an increased erythrocyte sedimentation rate was noted. She remained on treatment with $1 \mathrm{mg} / \mathrm{kg}$ amphotericin B therapy three times a week up to a total dose of $7 \mathrm{~g}$ in combination with $600 \mathrm{mg}$ daily itraconazole. At present, she receives no treatment, CT and technetium scintigraphy scans are negative and the erythrocyte sedimentation rate is normal more than 44 months after BMT.

Case 5 - Fusarium sp. A 21-year-old man initially misdiagnosed as a case of $\mathrm{Ph} 1$-positive undifferentiated acute leukemia was treated with conventional doses of cytarabine plus doxorubicin in February 1997. In May 1997, he had bone marrow relapse. Morphological, immunophenotyping and cytogenetic tests showed Ph1-positive ALL. He was submitted to the BFM-AR/83 protocol entering complete remission. On September 1997, he received an HLA-identical sibling allogeneic BMT. After day +100 , he experienced severe chronic GvHD that de-

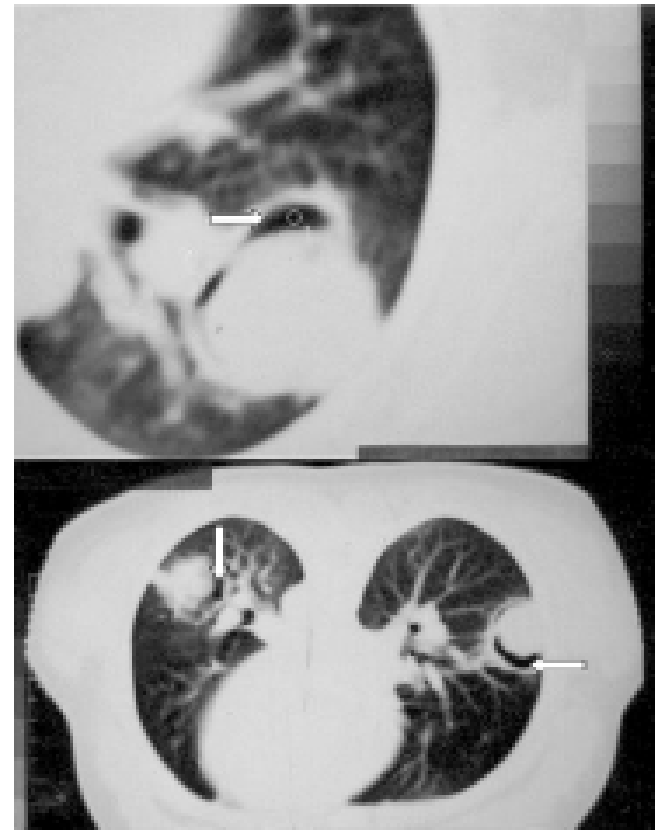

Figure 2. Case 2 (Aspergillus fumigatus). CT scan showing pulmonary lesions on air crescent, typical of invasive aspergillosis, involving both lungs.

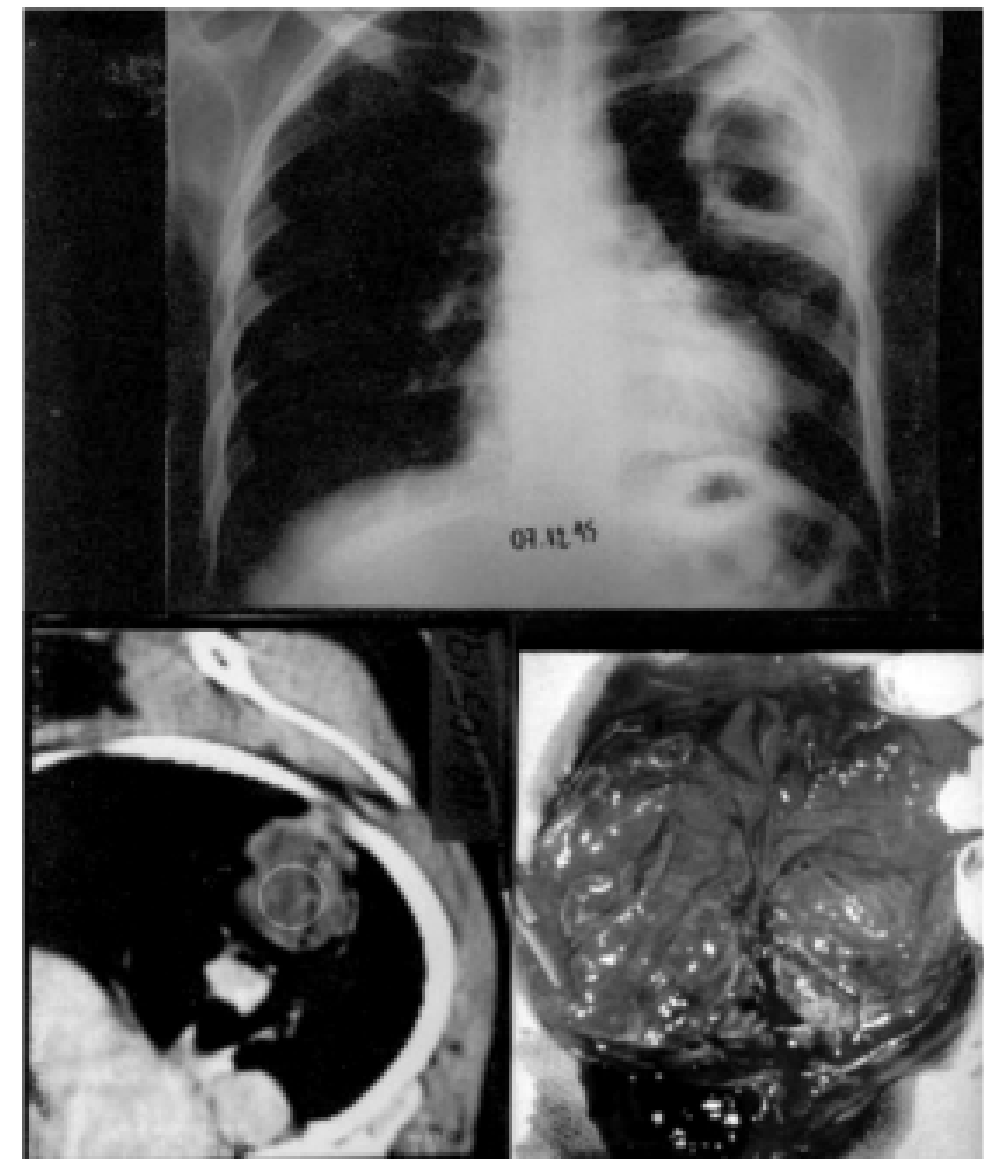

Figure 3. Case 3 (Rhizopus arrhizus). Details of the lung tumoral lesion: chest X-ray (upper panel), CT scan (lower left panel), and macroscopy (lower right panel). 
manded prolonged use of cyclosporin, 60 $\mathrm{mg}$ prednisone daily, $800 \mathrm{mg}$ of thalidomide daily plus an immunoglobulin course of $6 \mathrm{~g}$ a week. On day +370 , a testicular relapse of his leukemia was diagnosed. At that time, thalidomide, cyclosporin and prednisone were tapered, resulting in a remarkable increase of hepatic and skin GvHD lesions, but control of the relapse of leukemia through

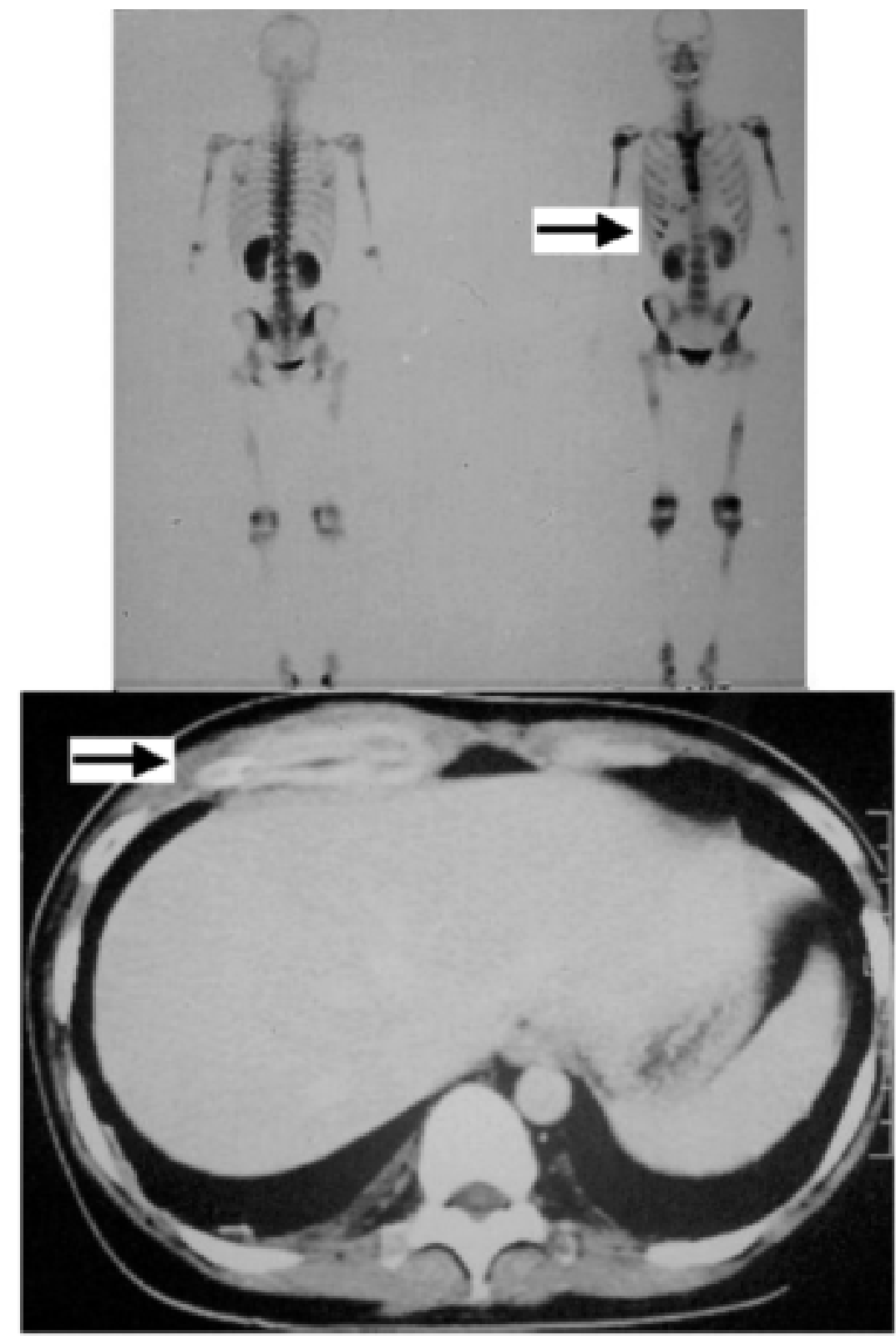

Figure 4. Case 4 (Aspergillus sp). The arrows show tumoral lesions involving right ribs identified during technetium scintigraphy (upper panel) and CT scan (lower panel). the graft-versus-leukemia effect. On day +471 , he suffered from generalized seizure episodes. A cranial CT scan demonstrated a right parietal hyperdense lesion. On day +477 , he developed multiple organ failure. Cultures from blood and CNS fluid yielded Fusarium sp.

\section{Discussion}

In the present series, five of 64 patients developed non-Candida fungal infections due to the following agents: Aspergillus sp (2), Fusarium sp (1), R. arrhizus (1) and $S$. prolificans (1). It is important to emphasize that the diagnosis of fungal infections was supported by culture and histopathological findings in four of the five cases reported. The diagnosis of rib osteomyelitis due to Aspergillus spp was based on the culture results of resected bones and local drainage samples as well as the clinical response to antifungal therapy.

Aspergillus infections have been reported in 3 to $7 \%$ of patients submitted to BMT and represent the second most common fungal infection among such patients. The other three agents documented in our series are less frequently reported and, consequently, reliable data showing their real incidence among BMT patients are lacking. In a series of 1186 BMT patients, zygomycosis agents caused only a $2 \%$ rate of non-Candida infections and no case of Scedosporium sp infection was documented, in contrast to a $70 \%$ rate of Aspergillus sp infection (2,3,6,1113).

Recipients of allogenic bone marrow graft present several particular risk factors for developing fungal infections, including chemotherapy before and during BMT (8), a prolonged period of mucositis and neutropenia (8), use of central venous catheters $(3,5$, $11)$, immunosuppressive therapy $(2,5,14)$, cytomegalovirus infection $(1-3,5,12)$, and development of GvHD $(1-3,5,12,15)$. Of note, the five cases of fungal infections presented 
here had several of the mentioned risk factors for developing such infections (see Table 1).

In case $1, S$. prolificans was isolated from a subcutaneous lesion. S. prolificans is an uncommon filamentous fungi that was first described in humans in 1984. S. prolificans has been isolated from plants and some domestic animals such as dogs and cats. In humans it has been related to three different clinical conditions: a) colonization, particularly of the respiratory tract, b) superficial and deep localized infections in immunocompetent or immunocompromised patients, and c) disseminated infections in immunosuppressed patients. Most of the patients with invasive localized or disseminated infections have AIDS, leukemia or lymphoma, or are recipients of organ transplants. Infections due to $S$. prolificans are generally refractory to antifungal therapy and the prognosis of disseminated infection due to $S$. prolificans is very poor (16-18).

Our patient infected with $S$. prolificans had a history of trauma causing the amputation of the distal phalanx of the second finger of the left hand, one year before being submitted to BMT. This operation may be considered the site of entry for this fungal pathogen. The fungal infection was observed after he developed diabetes with prednisone therapy and GvHD. The number of peripheral neutrophils and lymphocyte counts at the onset of fungal infection was within the normal range for the BMT course. We did not evaluate NK, CD4, CD29 or CD8 cells for any of our patients. However, we postulated that the association of steroid therapy with acute and chronic GvHD leads to a immunosuppression state and may have some influence on the evolution of fungal infection. Regarding his clinical outcome, in view of the usually unsuccessful antifungal therapy of invasive infections due to $S$. prolificans, a remarkable feature of this case was the clinical improvement obtained with itraconazole therapy.

Patient 2 exhibited numerous risk factors for Aspergillus infection, including a long period of hospitalization in the presence of a hospital construction area, prednisone and cyclosporin therapy. Early in the course of invasive aspergillosis, chest radiographs and sputum cultures are falsely negative and the diagnosis of invasive aspergillus infection is usually guided by findings of the chest CT scan. The presence of nodules with the halo sign or exhibiting the air crescent sign (as demonstrated in Figure 2) are radiological findings helpful for the diagnosis of invasive pulmonary aspergillosis. However, considering that other agents may mimic such radiological aspects, culture and histopathology data are needed to define the diagnosis of aspergillosis. The mortality of pulmonary aspergillosis is very high, especially among BMT patients. The patient was treated successfully with amphotericin B and by surgical resections of lung lesions, followed by long-term itraconazole maintenance treatment, as advocated by several authors $(3,4,10$ $12,19,20)$.

Case 4 developed an unusual clinical presentation of Aspergillus infection evolving soft tissue and ribs, near the outlet hole of the Hickman line. She had a partial response after antifungal therapy and surgical resection of the lesions. However, after discontinuation of antifungal therapy, there was a clinical relapse. At the time of the second resection of new lesions, it was not possible to demonstrate tissue invasion by the fungus. However, we should emphasize that she was on continuous antifungal therapy. Since Aspergillus spp had been isolated previously from two cultures, she was kept on amphotericin B therapy for a long period of time, with an accumulated dose of $7 \mathrm{~g}$. At present, she is no longer on antifungal therapy, with no signs of infections. Based on literature data and the outcome of the present patient, it is possible to say that bone aspergillosis has generally an unsuccessful outcome and demands not only long periods of antifungal drugs but also surgical resection of the le- 
sions $(6,19-21)$.

Patient 3 had a pulmonary zygomycosis, initially presenting as an upper lobe infiltrate that was negative when cultured for fungal isolates obtained by fiberoptic bronchoscopy with bronchoalveolar lavage and from a transbronchial biopsy. First, he was treated empirically for tuberculosis due to previous exposure to a family case of the disease. After developing severe extensive chronic GvHD and diabetes and receiving fluconazole and prednisone therapy, he evolved a cavitary lung lesion of the upper left lobe and was submitted to thoracotomy for surgical excision of the pulmonary lesion. Lung tissue culture yielded $R$. arrhizus, a finding compatible with the histological recognition of large aseptate hyphae seen in the lung sections. It is interesting to note that this patient had a previous history of extensive exposure to dusty material in his shoe shop. Unfortunately, the diagnosis was delayed due to misinterpretation of the first pulmonary lesions and to the initial results obtained by the bronchoalveolar lavage and the transbronchial biopsy. Zygomycosis is one of the most acute and fulminant fungal infections known and generally has a poor outcome, especially among severely immunocompromised patients $(9,14-17,22)$.

Case 5 exhibited a brain abscess due to Fusarium sp, a soil saprophyte and plant pathogen, which has been increasingly reported as an opportunistic agent of disseminated infection among neutropenic patients. The characteristic signs of this infection are skin lesions, fungemia and multiorgan involvement. This infection is usually refractory to all antifungal drug therapies and recovery of neutropenia is mandatory for clinical resolution (23). Few data are available about the involvement of the CNS by Fusarium spp. A review of 83 cases of invasive fusarial infections reported up to 1995 showed that only six (7\%) patients had CNS involvement. Brain abscess and meningitis following systemic invasive fusariosis have been reported $(2,3,24)$. The patient did not exhibit skin lesions, lung involvement or neutropenia, but Fusarium sp was recovered from blood and spinal fluid. Despite a high dose of amphotericin B, the patient died. He suffered from extensive chronic GvHD that showed a marked worsening after tapering the initial immunosuppression scheme, in order to treat the testicular relapse. The induction of a graft-versus-leukemia effect was successful, although it impaired his basic immunity due to the extensive GvHD, ensuing a fatal Fusarium sp infection (24).

Three episodes of Candida infections were also documented for two of the other 59 patients in our series. Two chronic CML patients had febrile episodes after the isolation of yeast from the Hickman lines and from blood cultures, and the fungal cultures grew $C$. albicans. The third episode of candidemia was preceded by the isolation of C. tropicalis from oral and gastrointestinal samples. At the time fluconazole was withdrawn due to multidrug acute hepatitis. The patient then suffered complication with candidemia due to $C$. tropicalis. All three patients had a successful outcome with amphotericin B therapy. It is remarkable that fluconazole prophylaxis indeed decreased the incidence of Candida sp infections among such risk patients $(3-5,8,11)$. However, it should be emphasized that such prophylaxis cannot prevent other opportunistic fungal infections, such as zygomycosis, aspergillosis and Fusarium sp infections $(4,8,25)$.

We also should mention that this uncontrolled study was conducted in the setting of a developing country where social and economic factors have a strong influence on routine clinical care. Cost factors were considered by the clinical staff when they decided to use $200 \mathrm{mg} /$ day instead of $400 \mathrm{mg} /$ day fluconazole.

It is noteworthy that all eight episodes of invasive infections in the present material were diagnosed after the neutropenic posttransplant period. The median time from 
transplant to the diagnosis of the fungal infections was 138 days after BMT, ranging from 29 to 471 days. A significant number of fungal infections occurred late after BMT and were associated with GvHD and its treatment.

Finally, the occurrence of severe nonCandida infections highly refractory to available antifungal drugs should alert the clinicians to the need to develop new strategies for the prophylaxis and therapy of fungal infections. Recently, several new antifungal drugs have been tested in humans in developing countries, including a parenteral itraconazole formulation (Jansen Pharmaceuti- cal, São Paulo, SP, Brazil), voriconazole (Pfizer, Guarulhos, SP, Brazil), posaconazole (Schering, São Paulo, SP, Brazil), ravuconazole (Bristol-Myers Squibb, São Paulo, SP, Brazil), caspofungin (Merck Sharp \& Dhome, São Paulo, SP, Brazil) and FK463 (Fujisawa, Deerfield, IL, USA). All of these compounds are very active against Candida spp and Aspergillus spp. Actually, voriconazole and posaconazole have also demonstrated some activity against isolates of Scedosporium spp and Fusarium spp. Hopefully, all of these drugs will enhance the clinician's ability to care for patients with invasive fungal infections (26).

\section{References}

1. Guiot HFL, Fibbe WE \& van't Wout JW (1994). Risk factors for fungal infection in patients with malignant hematological disorders: implications for empirical therapy and prophylaxis. Clinical Infectious Diseases, 18: 525-532.

2. Morrison VA, Haake RJ \& Weisdorf DJ (1994). Non-Candida fungal infections after bone marrow transplantation: risk factors and outcome. American J oumal of Medicine, 96: 497-503.

3. J antunen E, Ruutu P, Niskanen L, Volin L, Parkkali T, Koukila-Kahkola P \& Ruutu T (1997). Incidence and risk factors for invasive fungal infections in allogeneic BMT recipients. Bone Marrow Transplantation, 19: 801-808.

4. Baron O, Guillaumé B, Moreau $P$, Germaud P, Despins P, De Lajartre AY \& Michaud J L (1998). Aggressive surgical management in localized pulmonary mycotic and nonmycotic infections for neutropenic patients with acute leukemia: report of eighteen cases. J ournal of Thoracic and Cardiovascular Surgery, 115: 6369.

5. Mehta J, Kesley S, Chu P, Powles R, Hazel D, Riley U, Evans C, Newland A, Treleaven J \& Singhal S (1997). Amphotericin B lipid complex (ABLC) for the treatment of confirmed or presumed fungal infections in immunocompromised patients with hematological malignancies. Bone Marrow Transplantation, 20: 39-43.

6. Verschraegen $\mathrm{CF}$, Van Besien $\mathrm{KW}$, Dignani C, Hester J P, Anderson BS \&
Anaissie E (1997). Invasive Aspergillus sinusitis during bone marrow transplantation. Scandinavian J ournal of Infectious Diseases, 29: 436-438.

7. Witzig R, Greer D \& Hyslop E (1996). Aspergillus flavus mycetoma and epidural abscess successfully treated with itraconazole. J ournal of Medical and Veterinary Mycology, 34: 133-137.

8. Choi JH, Yoo JH, Chung IJ, Kim DW, Ham CW, Shin WS, Min WS, Park CW, Kim CC \& Kim DJ (1997). Esophageal aspergillosis after bone marrow transplant. Bone Marrow Transplantation, 19: 293294.

9. Tedder M, Spratt J A, Anstadt MP, Hegde SS, Tedder SD \& Lowe J E (1994). Pulmonary mucormycosis: results of medical and surgical treatment. Annals of Thoracic Surgery, 57: 1044-1050.

10. Hagensee $M$, Bauwens J, Kjos B \& Bowden RA (1994). Brain abscess following marrow transplantation: experience at the Fred Hutchinson 1984-1992. Clinical Infectious Diseases, 19: 402-408.

11. Wald A, Leisenring W, Van Burik J \& Bowden RA (1997). Epidemiology of aspergillus infections in a large cohort of patients undergoing bone marrow transplantation. J ournal of Infections Diseases, 175: 1459-1466.

12. McWhinney PHM, Kibbler CC, Hamon MD, Smith OP, Gandhi L, Berger LA, Walesby RK, Hoffbrand AV \& Prentice HG (1993). Progress in the diagnosis and management of aspergillosis in bone marrow transplantation: 13 years experience. Clinical Infectious Diseases, 17: 397-404.

13. Hosking $\mathrm{M}, \mathrm{MacDonald} \mathrm{N} \&$ Cornel $\mathrm{G}$ (1995). Liposomal amphotericin B for postoperative Aspergillus fumigatus endocarditis. Annals of Thoracic Surgery, 59: 1015-1017.

14. Nomura J , Ruskin J , Sahebi F, Kogut N \& Falk PM (1997). Mucormycosis of the vulva following bone marrow transplantation. Bone Marrow Transplantation, 19: 859-860.

15. J antunen E, Kolho E, Ruutu P, KoukilaKahkola $P$, Virolainen $M$, J uvonen $E$ \& Volin L (1996). Invasive cutaneous mucormycosis caused by Absidia corymbifera after bone marrow transplantation. Bone Marrow Transplantation, 18: 229-230.

16. Farag S, Firkin F, Andrew J , Lee CS \& Ellis DH (1992). Fatal disseminated Scedosporium inflatum infection in a neutropenic immunocompromised patient. J ournal of Infection, 25: 201-204.

17. Dupont B, Improvisi L \& Ronin O (1991). Aspects épidemiologiques et cliniques des infections a Scedosporium et a Pseudallescheria. J ournal of Mycology Medicine, 118: 33-42.

18. Idigoras $P$, Pérez-Trallero $E$, Piñero $L$, Larruskain J , López-Lopategui MC, Rodriguez N \& Gonzáles J M (2001). Disseminated infection and colonization by Scedosporium prolificans: a review of 18 cases, 1990-1999. Clinical Infectious Diseases, 32: 158-165.

19. Savage D, Taylor P, Blackwell J , Chen F, 
Szydlo RM, Rule SAJ, Spencer A, Apperley J F \& Goldman J M (1997). Para nasal sinusitis following allogeneic bone marrow transplant. Bone Marrow Transplantation, 19: 55-59.

20. Catalano L, Fontana R, Scarpato N, Picardi M, Rocco S \& Rotoli B (1997). Combined treatment with amphotericin $B$ and granulocyte transfusion from G-CSF-stimulated donors in an aplastic patient with invasive aspergillosis undergoing bone marrow transplantation. Haematologica, 82: 71 72.

21. Anaissie E, Vartivarian S, Abi-Said D, Uzun $\mathrm{O}$, Pinczowsi $\mathrm{H}$, Kontoyiannis DP, Khoury P, Papadakis K, Gardner A, Raad II,
Gilbreath J \& Bodey GP (1996). Fluconazole versus amphotericin $B$ in the treatment of hematogenous candidiasis: A matched cohort study. American J oumal of Medicine, 101: 170-176.

22. Gaziev D, Baronciani D, Galimberti M, Polchi P, Angelucci E, Giardini C, Muretto P, Penugini S, Riggio S, Ghirlanda S, Erer B, Maiello A \& Lucarelli G (1996). Mucormycosis after bone marrow transplantation: report of four cases in thalassemia and review of the literature. Bone Marrow Transplantation, 17: 409-414.

23. Boutati El \& Anaissie EJ (1997). Fusarium, a significant emerging pathogen in patients with hematologic malignancy: Ten years' experience at a cancer center and implications for management. Blood, 90: 999-1008.

24. Guarro J \& Gené J (1995). Opportunistic fusarial infections in humans. European J oumal of Clinical Microbiology and Infectious Diseases, 14: 741-754.

25. Piliero P \& Deresiewicz R (1995). Pulmonary zygomycosis after allogeneic bone marrow transplantation. Southem Medical J oumal, 88: 1149-1152.

26. Neely MN \& Ghannoum MA (2000). The exciting future of antifungal therapy. European J ournal of Clinical Microbiology and Infectious Diseases, 19: 897-914. 